\title{
PENGARUH MANAJEMEN PERUBAHAN, BUDAYA ORGANISASI DAN KUALITAS KERJA TERHADAP KINERJA PEGAWAI BADAN PENYELENGGARA JAMINAN SOSIAL (BPJS) KESEHATAN CABANG PADANG SIDEMPUAN
}

\author{
Yasmine Ramadhana Harahap \\ Universitas Islam Sumatera Utara \\ yasmine.ramadhan@gmail.com
}

\begin{abstract}
One of the keys to a company's success is to depend on good employee performance and harmoniously intertwined directly or indirectly contribute to offices that include internal and external interests that are owned by offices. For this reason, in improving employee performance, it is necessary to manage changes and organizational culture that can affect performance, because many employees have different attitudes, different cultural backgrounds, and different understandings that can affect employee performance in an organization. For this reason, in improving employee performance, it is necessary to manage changes and organizational culture that can affect performance, because many employees have different attitudes, different cultural backgrounds, and different understandings that can affect employee performance in an organization.

Based on the results of the equation, the following explanation can be described: Constant value of 46.243 means that if the overall value of the variable (Management of Change X1, Organizational Culture X2, Quality of Work X3) rises by la respectively, the value of Performance $(Y)$ will rise to 46,243. Change Management by 0.220 means that if the Change Management value increases by la then the performance value will also increase by 0.220. A positive coefficient value means that Change Management has a positive influence on performance. Organizational Culture coefficient value of 0.543 means that if the Organizational Culture value increases by $1 a$, the performance value will also increase by 0.543. A positive coefficient value means that Organizational Culture has a positive influence on Performance. The coefficient of Work Quality value of 0.482 means that if the value of Work Quality rises by 1a, the value of performance will also increase by 0.482. A positive coefficient value gives the meaning that Work Quality has a positive influence on Performance.
\end{abstract}

Keywords: Change Management, Organizational Culture, Work Quality

ABSTRAK : Salah satu kunci keberhasilan suatu perusahaan adalah bergantung pada kinerja pegawai yang baik dan terjalin harmonis secara langsung atau tidak langsung memberikan kontribusi kepada perkantoran yang meliputi kepentingan internal dan eksternal yang dimiliki oleh perkantoran. Untuk itu dalam meningkatkan kinerja pegawai perlunya manajamen perubahan dan budaya organisasi yang dapat mempengaruhi kinerja, karena banyak pegawai yang memiliki sikap yang berbeda, latar belakang budaya yang berbeda, dan paham yang berbeda yang dapat berpengaruh untuk kinerja pegawai pada suatu organisasi. Untuk itu dalam meningkatkan kinerja pegawai perlunya manajamen perubahan dan budaya organisasi yang dapat mempengaruhi kinerja, karena banyak pegawai yang memiliki sikap yang berbeda, latar belakang budaya yang berbeda, dan paham yang berbeda yang dapat berpengaruh untuk kinerja pegawai pada suatu organisasi.Kinerja $=46,243 C+, 220 X^{1}+, 543 X^{2}+, 482 X^{3}$. Berdasarkan hasil persamaan tersebut maka dapat diuraikan penjelasan sebagai berikut :Nilai Konstanta sebesar 46,243 memberikan arti bahwa jika secara keseluruhan nilai variable (Manajemen PerubahanX ${ }^{1}$, Budaya Organisasi $X^{2}$, Kualitas Kerja $X^{3}$ ) naik masing sebesar $1_{a}$ maka nilai Kinerja $(Y)$ akan naik menjadi 46,243.Nilai koefisien Manajemen Perubahan sebesar 0,220 memberikan arti bahwa jika nilai Manajemen Perubahan naik sebesar $1_{a}$ maka nilai kinerja juga akan naik sebesar 0,220 . Nilai koefisien yang positif memberikan arti bahwa Manajemen Perubahan memberikan pengaruh 
positif terhadap Kinerja.Nilai koefisien Budaya Organisasi sebesar 0,543 memberikan arti bahwa jika nilai Budaya Organisasi naik sebesar $1_{a}$ maka nilai kinerja juga akan naik sebesar 0,543. Nilai koefisien yang positif memberikan arti bahwa Budaya Organisasi memberikan pengaruh positif terhadap Kinerja.Nilai koefisien Kualitas Kerja sebesar 0,129 memberikan arti bahwa jika nilai Kualitas Kerja naik sebesar $1_{a}$ maka nilai kinerja juga akan naik sebesar 0,129. Nilai koefisien yang positif memberikan arti bahwa Kualitas Kerja memberikan pengaruh positif terhadap Kinerja.

\section{Kata Kunci : Manajemen Perubahan, Budaya Organisasi, Kualitas Kerja}

\section{Pendahuluan}

Salah satu kunci keberhasilan suatu perusahaan adalah bergantung pada kinerja pegawai yang baik dan terjalin harmonis secara langsung atau tidak langsung memberikan kontribusi kepada perkantoran yang meliputi kepentingan internal dan eksternal yang dimiliki oleh perkantoran. Kinerja yang baik merupakan hasil secara kualitas dan kuantitas yang dicapai oleh seorang pegawai dalam melaksanakan tugasnnya sesuai dengan tanggung jawab yang diberikan kepadanya maka perkantoran perlu menetapkan strategi yang tepat yaitu dengan cara memahami beberapa faktor yang mempengaruhi pencapaian kinerja antara lain efektifitas, otoritas, tanggung jawab, disiplin dan inisiatif (Haryati, 2013 : 131).

Upaya menciptakan kinerja pegawai bukanlah hal yang mudah, karena dalam kenyataannya masih banyak pegawai yang kinerjanya kurang optimal seperti pelayanan, pencapaian target, malas dan masih kurang bertanggungjawab dalam menyelesaikan pekerjaan. Untuk itu dalam meningkatkan kinerja pegawai perlu nyaman dan budaya organisasi yang dapat mempengaruhi kinerja, karena banyak pegawai yang memiliki sikap yang berbeda, latar belakang budaya yang berbeda, dan paham yang berbeda yang dapat berpengaruh untuk kinerja pegawai pada suatu organisasi. Hal ini menuntut perusahaan untuk membekali sumberdaya manusia yang ada di dalam perusahaan agar dapat bekerja secara efektif dan efisien sehingga mampu meningkatkan kinerja.

Faktor yang mempengaruhi kinerja pegawai adalah Manajemen Perubahan. Manajemen perubahan merupakan suatu proses sistematis dalam menerapkan pengetahuan, sarana, dan sumberdaya untuk mempengaruhi perubahan pada orang yang akan terkena dampak dari proses tersebut. (Haryono,2015:35). Manajemen perubahan serta budaya organisasi saat ini masih terlalu baku berdasarkan pada konsep yang dapat menjadi sarana untuk mengukur kesesuaian dari tujuan organisasi tanpa melihat latar belakang atau pun observasi personal yang langsung melibatkan seluruh SDM yang ada pada BPJS Kesehatan Di dalam pengelolahan SDM, apabila individu dalam organisasi yaitu sumberdaya manusianya dapat berjalan efektif maka organisasi tetap berjalan efektif. Beberapa kegiatan pengelolahan SDM misalnya pengadaan, penilaian, perlindungan, memotivasi pegawai, memberdayakan pegawai, peningkatan disiplin, bimbingan, dll. Pengelolaan dan pengoptimalan sumberdaya manusia tidak lepas dari factor pegawai. Organisasi harus mempunyai pegawai mempunyai kinerja yang baik. Dengan kata lain kelangsungan suatu organisasi ditentukan oleh kinerja pegawainya (Widarno, 2016;124).

Menurut penelitian (Suharti,2012:48) menjelaskan bahwa kinerja merupakan suatu fungsi kemampuan pekerja dalam menerima tujuan pekerjaaan, tingkat pencapain tujuan dan interaksi antara tujuan dan kemampuan pekerja. Dengan definisi tersebut dapat dikatakan bahwa pegawai memegang peranan penting dalam menjalankan segala aktivitas perkantoran. Penelitian (Hidayati,2014;42) menegaskan bahwa kinerja sebagai hasil kerja seseorang atau sekelompok orang dalam suatu organisasi dengan wewenang dan tanggung jawab masing-masing dalam upaya mencapai tujuan organisasi secara ilegal, tidak melanggar hukum, dan sesuai dengan moral dan etika. Kinerja pegawai adalah yang mempengaruhi seberapa banyak mereka member kontribusi kepada organisasi atau perbaikan kinerja baik untuk individu maupun kelompok menjadi pusat perhatian dalam upaya meningkatkan kinerja organisasi.

Pokok permasalahan yang terjadi dilingkungan kerja BPJS Kesehatan Cabang Padang Sidimpuan adalah Manajemen perubahan belum optimal disebabkan terlalu dinamis sehingga pembaharuan belum tuntas, pembaharuan berikutnya sudah kembali untuk 
dilaksanakan. Pegawai tidak siap untuk beradaptasi dengan adanya kecepatan perubahan dalam lingkungan kerja. Sedangkan dalam Budaya Organisasi juga belum optimal di karenakan penerapan sanksi bagi yang melanggar belum benar-benar dilaksanakan sehingga menjadi contoh buruk kepada pegawai yang lain. Hal tersebut dapat menjadi contoh untuk ditiru oleh pegawai lain yang mengakibatkan budaya organisasi yang diharapkan tidak berjalan optimal yang jelasjelas terkait dengan Kualitas kerja pegawai. Analisa beban kerja juga belum optimal dilakukan akibatnyapekerjaan dilakukan tumpang tindih sehingga banyak pekerjaan yang terbengkalai, pelayanan yang seharusnya menjadi pokok utama dalam pekerjaan tidak dapat terlaksana dengan maksimal, kualitas kerja semakin buruk hasilnya. Rotasi/mutasi pegawai kurang dipertimbangkan berdasarkan minat, kompetensi dan dasar keilmuan yang dimilikipegawai sehingga mempengaruhi kualitas kerja dan passion terhadap job desk yang diberikan didalam lingkungan kerja menjadi tidak teratur sehingga kualitas kerja tidak tercapai taget yang diharapkan. Selanjutnya berdampak juga pada perubahan struktur organisasi yang terlalu cepat tanpa adanya rentang kendali dan melibatkan hampir seluruh SDM pada BPJS Kesehatan yang mengakibatkan perubahan Distinct Job Profile seluruh jabatan yang ada di BPJS Kesehatan sehingga seluruh SDM perlu penyesuaian kembali terhadap pekerjaan masing-masing.

Oleh karena itu, berdasarkan uraian permasalahan tersebut diatas peneliti tertarik untuk melakukan penelitian mengenai Pengaruh Manajemen Perubahan, Budaya Organisasi dan Kualitas Kerja terhadap Kinerja pegawai Badan Penyelenggara Jaminan Sosial (BPJS) Kesehatan Cabang Padang Sidimpuan.

Berdasar pada judul penelitian diatas, maka diambil tujuan penelitian sebagai berikut :

1. Untuk menganalisis pengaruh manajemen perubahan terhadap kinerja pegawai Badan Penyelenggara Jaminan Sosial (BPJS) Kesehatan Cabang Padang Sidimpuan.

2. Untuk menganalisis pengaruh budaya organisasi terhadap kinerja pegawai Badan Penyelenggara Jaminan Sosial (BPJS) Kesehatan Cabang Padang Sidimpuan.

3. Untuk menganalisis pengaruh kualitas kerja terhadap kinerja pegawai Badan Penyelenggara Jaminan Sosial (BPJS) Kesehatan Cabang Padang Sidimpuan.
4. Untuk menganalisis pengaruh manajemen perubahan, budaya organisasi dan kualitas kerja terhadap kinerja pegawai Badan Penyelenggara Jaminan Sosial (BPJS) Kesehatan Cabang Padang Sidimpuan.

\section{Metode Penelitian}

\subsection{Populasi dan Sampel}

Populasi merupakan subjek penelitian dimana individu yang akan dikenai perilaku atau dapat dikatakan sebagai keseluruhan objek penelitian yang akan diteliti. Populasi pada penelitian ini adalah pegawai di Badan Penyelenggara Jaminan Sosial (BPJS) Kesehatan Cabang Padang Sidimpuan.

Sampel pada penelitian ini menggunakan teknik total sampling, sehingga jumlah sampel pada penelitian ini sebanyak 42 orang.

\subsection{Pengujian Validitas}

Dalam penelitian ini nilai validitas dicari dengan menggunakan rumus korelasi product moment dari Pearson.Penafsiran harga koefisien korelasi dilakukan dengan membandingkan harga $r_{x y}$ dengan harga kritik. Harga kritik untuk validitas butir instrument adalah 0,3 . Artinya apabila $r_{x y}$ lebih besar atau sama dengan $0,3\left(\mathrm{r}_{\mathrm{xy}} \geq 0,3\right)$ maka nomor butir dapat dikatakan valid. Sebaliknya apabila $r_{x y}$ lebih kecil dari $0,3\left(r_{x y} \leq 0,3\right)$ maka nomor butir dapat dikatakan tidak valid. Suharsimi (2010). Uji validitas dilakukan dengan menggunakan program SPSS 24.

Tabel 1

Uji Validitas Variabel $\mathrm{X}_{1}$

\begin{tabular}{|c|c|c|c|}
\hline Pertanyaan & $\mathbf{r}_{\text {hitung }}$ & $\mathbf{r}_{\text {tabel }}$ & Keterangan \\
\hline 1 & 0,217 & 0,220 & Valid \\
\hline 2 & 0,303 & 0,220 & Valid \\
\hline 3 & 0,381 & 0,220 & Valid \\
\hline 4 & 0,501 & 0,220 & Valid \\
\hline 5 & 0,428 & 0,220 & Valid \\
\hline 6 & 0,339 & 0,220 & Valid \\
\hline 7 & 0,446 & 0,220 & Valid \\
\hline 8 & 0,505 & 0,220 & Valid \\
\hline 9 & 0,498 & 0,220 & Valid \\
\hline 10 & 0,050 & 0,220 & Valid \\
\hline
\end{tabular}

Sumber: data yang diolah 2019

Tabel 2

Uji Validitas Variabel $\mathrm{X}_{2}$

\begin{tabular}{|c|c|c|c|}
\hline Pertanyaan & $\mathbf{r}_{\text {hitung }}$ & $\mathbf{r}_{\text {tabel }}$ & Keterangan \\
\hline 1 & 0,467 & 0,220 & Valid \\
\hline 2 & 0,397 & 0,220 & Valid \\
\hline 3 & 0,702 & 0,220 & Valid \\
\hline 4 & 0,743 & 0,220 & Valid \\
\hline
\end{tabular}




\begin{tabular}{|c|c|c|c|}
\hline Pertanyaan & $\mathbf{r}_{\text {hitung }}$ & $\mathbf{r}_{\text {tabel }}$ & Keterangan \\
\hline 5 & 0,818 & 0,220 & Valid \\
\hline 6 & 0,609 & 0,220 & Valid \\
\hline 7 & 0,574 & 0,220 & Valid \\
\hline 8 & 0,797 & 0,220 & Valid \\
\hline 9 & 0,505 & 0,220 & Valid \\
\hline 10 & 0,691 & 0,220 & Valid \\
\hline
\end{tabular}

Sumber: data yang diolah 2019

Tabel 3

Uji Validitas Variabel $\mathrm{X}_{3}$

\begin{tabular}{|c|c|c|c|}
\hline Pertanyaan & $\mathbf{r}_{\text {hitung }}$ & $\mathbf{r}_{\text {tabel }}$ & Keterangan \\
\hline 1 & 0,459 & 0,220 & Valid \\
\hline 2 & 0,595 & 0,220 & Valid \\
\hline 3 & 0,490 & 0,220 & Valid \\
\hline 4 & 0,570 & 0,220 & Valid \\
\hline 5 & 0,625 & 0,220 & Valid \\
\hline 6 & 0,668 & 0,220 & Valid \\
\hline 7 & 0,674 & 0,220 & Valid \\
\hline 8 & 0,631 & 0,220 & Valid \\
\hline 9 & 0,666 & 0,220 & Valid \\
\hline 10 & 0,616 & 0,220 & Valid \\
\hline
\end{tabular}

Sumber: data yang diolah 2019
Tabel 4

Uji Validitas Variabel Y

\begin{tabular}{|c|c|c|c|}
\hline Pertanyaan & $\mathbf{r}_{\text {hitung }}$ & $\mathbf{r}_{\text {tabel }}$ & Keterangan \\
\hline 1 & 0,552 & 0,220 & Valid \\
\hline 2 & 0,668 & 0,220 & Valid \\
\hline 3 & 0,649 & 0,220 & Valid \\
\hline 4 & 0,714 & 0,220 & Valid \\
\hline 5 & 0,774 & 0,220 & Valid \\
\hline 6 & 0,617 & 0,220 & Valid \\
\hline 7 & 0,587 & 0,220 & Valid \\
\hline 8 & 0,566 & 0,220 & Valid \\
\hline 9 & 0,468 & 0,220 & Valid \\
\hline 10 & 0,600 & 0,220 & Valid \\
\hline
\end{tabular}

Sumber: data yang diolah 2019

Dari table diatas terlihat bahwa nilai rhitung $>$ rtabel, maka dapat disimpulkan semua item pertanyaan dinyatakan valid.

\subsection{Uji Reliabilitas}

Dalam penelitian ini uji reliabilitas dicari menggunakan rumus Alpha.Rumus Alpha digunakan untuk mencari reliabilitas instrumen yang skornya bukan 1 dan 0 . Instrumen dapat dikatakan reliabel jika nilai koefisien alpha tersebut melebihi 0,6 (Santoso, Singgih 2010). Tabel 5

Hasil Uji Reliabilitas instrument

\begin{tabular}{|c|c|c|c|}
\hline Variabel & $\begin{array}{c}\text { Nilai Alfa } \\
\text { Cronbach }\end{array}$ & $\begin{array}{c}\text { CronbachAlfa } \\
\text { Standard }\end{array}$ & Keterangan \\
\hline Manajemen Perubahan & 0,624 & 0,600 & Reliabel \\
\hline Budaya Organisasi & 0,756 & 0,600 & Reliabel \\
\hline Kualitas Kerja & 0,746 & 0,600 & Reliabel \\
\hline Kinerja Pegawai & 0,754 & 0,600 & Reliabel \\
\hline
\end{tabular}

Sumber: Data yang diolah 2019

\subsection{Uji Asumsi Klasik}

\subsubsection{Uji Normalitas}

Adapun hasil pengujian Normalitas dalam penelitian ini menggunakan pendekatan grafik dengan P-P Plot dan juga uji yang dapat pada gambar berikut;

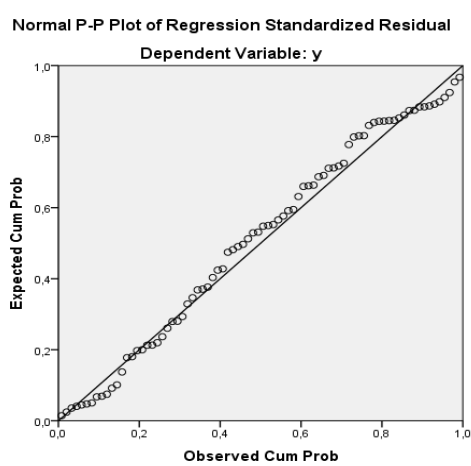

Gambar 1. Hasil Uji Normalitas dengan P-P Plot
Berdasarkan hasil uji normalitas dengan P-P Plot pada gambar diatas dapat dilihat bahwa plot menyebar mengikuti atau searah dengan garis diagonal, sehingga dapat disimpulkan bahwa model regresiyang digunakan dalam penelitian ini normal dan dapat digunakan.

\subsubsection{Uji Multikolinearitas}

Adapun hasil pengujian Multikolinearitas dalam penelitian ini dapat dilihat pada table berikut : 
Hasil Uji Multikolinearitas

Coefficients ${ }^{\mathrm{a}}$

\begin{tabular}{|c|c|c|c|c|c|}
\hline \multirow{2}{*}{ Variable } & \multicolumn{2}{|c|}{$\begin{array}{c}\text { Unstandardized } \\
\text { Coefficients }\end{array}$} & $\begin{array}{c}\text { Standardized } \\
\text { Coefficients }\end{array}$ & \multicolumn{2}{c|}{ Collinearity Statistics } \\
\cline { 2 - 6 } & B & Std. Error & Beta & Tolerance & VIF \\
\hline (Constant) & 46,243 & 18,241 & & & \\
\hline X1 &, 220 &, 337 &, 104 &, 998 & 1,002 \\
\hline X2 &, 543 &, 166 &, 138 &, 983 & 1,018 \\
\hline X3 &, 482 &, 169 &, 004 &, 982 & 1,018 \\
\hline
\end{tabular}

Dari table diatas terlihat bahwa nilai Variance Inflation Factor (VIF) <10, maka hal ini tidak terjadi multikolinearitas.

\subsubsection{Uji Heteroskedastisitas}

Adapun hasil pengujian heteroskedastisitas dalam penelitian ini dapat dilihat pada gambar berikut :

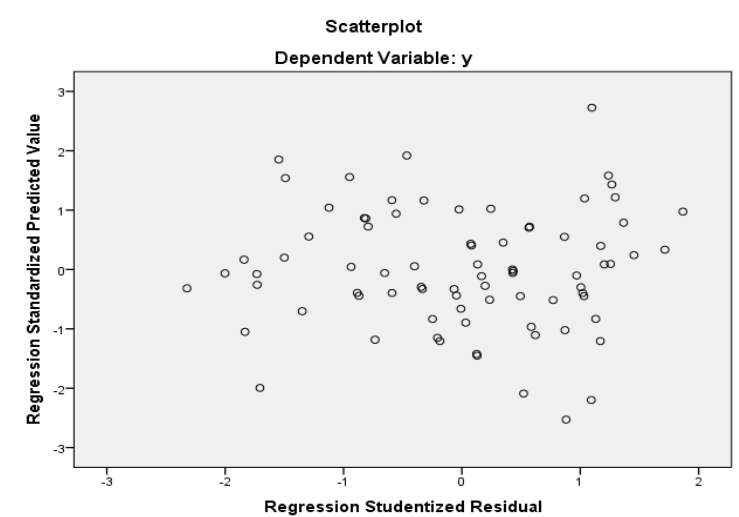

Berdasarkan hasil pengujian heteroskedastisitas pada gambar diatas dapat dilihat bahwa plot menyebar secara acak di antara sumbu $\mathrm{X}$ dan $\mathrm{Y}$ sehingga dapat disimpulkan bahwa tidak terdapat gejala heteroskedastisitas pada model regresi yang digunakan dalam penelitian ini dan model regresi telah memenuhi syarat uji heteroskedastisitas.

\subsection{Analisis Regresi Linear Berganda}

Analisis Regresi Linier Berganda digunakan untuk mengetahui pegaruh manajemen perubahan, budaya organisasi dan kualitas kerja terhadap kinerja pegawai, dapat dilihat dari persamaan regresinya, dan dari output program SPSS diperoleh data sebagai berikut

Gambar 2. Hasil Uji Heteroskedastisitas dengan Scatter Plot

Tabel 7

Regresi Linear Berganda

\begin{tabular}{|c|c|c|c|c|c|c|}
\hline \multirow{2}{*}{\multicolumn{2}{|c|}{ Model }} & \multicolumn{2}{|c|}{ Unstandardized Coefficients } & \multirow{2}{*}{$\begin{array}{c}\text { Standardized } \\
\text { Coefficients } \\
\text { Beta }\end{array}$} & \multirow{2}{*}{$\mathrm{t}$} & \multirow{2}{*}{ Sig. } \\
\hline & & $\mathrm{B}$ & Std. Error & & & \\
\hline \multirow{4}{*}{1} & (Constant) & 13.818 & 1.985 & & 6.962 & .000 \\
\hline & $\mathrm{X} 1$ & .220 & .068 & .356 & 3.261 & .002 \\
\hline & $\mathrm{X} 2$ & .249 & .072 & .337 & 3.466 & .001 \\
\hline & X3 & .212 & .053 & .425 & 4.000 & .000 \\
\hline
\end{tabular}

Berdasarkan Tabel 7 diatas dapat dibuat persamaan regresi sebagai berikut :

$Y=13.818+0.220 X_{1}+0.249 X_{2}+0.212 X_{3}$

a) Nilai kinerja pegawai di Badan

Penyelenggara Jaminan Sosial (BPJS)

Kesehatan Cabang Padang Sidimpuan sebesar 13.818, yang mana nilai dari variabel manajemen perubahan, budaya organisasi dan kualitas kerja diabaikan.

b) Persamaan di atas menjelaskan bahwa koefisien regresi $\mathrm{X}_{1}$ (manajemen perubahan) mempunyai nilai positif yaitu 0.220 , hal ini menunjukkan bahwa variabel manajemen perubahan mempunyai pengaruh positif terhadap kinerja pegawai, bila manajemen 
perubahan meningkat $1 \%$, maka kinerja pegawai akan bertambah $22.0 \%$.

c) Persamaan di atas menjelaskan bahwa koefisien regresi $\mathrm{X}_{2}$ (budaya organisasi) mempunyai nilai positif yaitu 0.249 , hal ini menunjukkan bahwa variabel budaya organisasi mempunyai pengaruh positif terhadap kinerja pegawai, bila budaya organisasi meningkat $1 \%$, maka kinerja pegawai akan bertambah $24.9 \%$.

d) Persamaan di atas menjelaskan bahwa koefisien regresi $\mathrm{X}_{3}$ (kualitas kerja) mempunyai nilai positif yaitu 0.212 , hal ini menunjukkan bahwa variabel kualitas kerja mempunyai pengaruh positif terhadap kinerja pegawai, bila kualitas kerja meningkat $1 \%$, maka kinerja pegawai akan bertambah $21.2 \%$.

\subsection{Uji Signifikan Simultan (Uji F)}

Tabel 8

Hasil Uji Serempak

ANOVA $^{\mathrm{a}}$

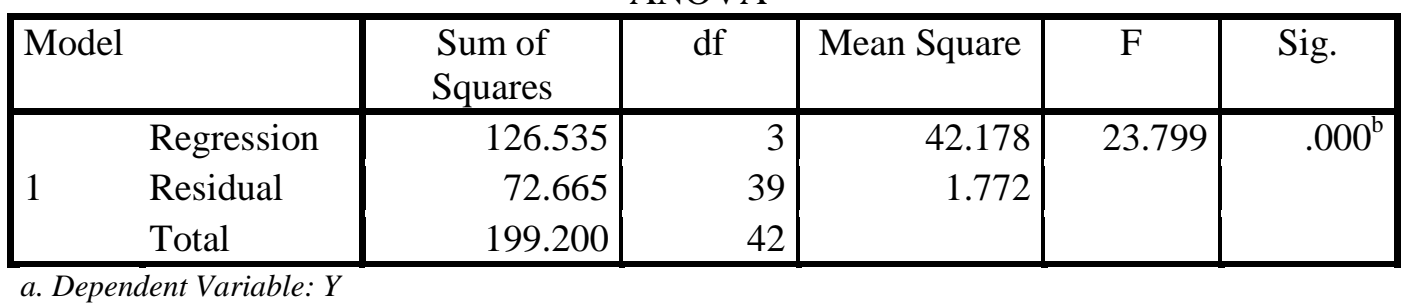

b. Predictors: (Constant), X3, X2, X1

Berdasarkan tabel 8 di atas dapat dilihat bahwa Fhitung sebesar 23.799 sedangkan Ftabel sebesar 2,81 dengan nilai probabilitas 0.05. Probabilitas siginifikan jauh lebih kecil dari 0,05 yaitu $0,000<0,05$, maka model regresi dapat dikatakan bahwa dalam penelitian ini manajemen perubahan, budaya organisasi dan kualitas kerja secara simultan berpengaruh signifikan terhadap kinerja pegawai. Maka hipotesis sebelumnya adalah Terima Ha (tolak H0) atau hipotesis diterima

\subsection{Uji Signifikan Parsial (t)}

Uji pengaruh variabel pengaruh manajemen perubahan, budaya organisasi dan kualitas kerja terhadap kinerja pegawai secara parsial dapat dilihat pada tabel berikut :

Tabel 9

Uji Parsial (Uji t)

\begin{tabular}{|c|c|c|c|c|c|c|}
\hline \multirow{2}{*}{\multicolumn{2}{|c|}{ Model }} & \multicolumn{2}{|c|}{ Unstandardized Coefficients } & \multirow{2}{*}{$\begin{array}{c}\text { Standardized } \\
\text { Coefficients }\end{array}$} & \multirow[t]{2}{*}{$\mathrm{t}$} & \multirow[t]{2}{*}{ Sig. } \\
\hline & & B & Std. Error & & & \\
\hline \multirow{4}{*}{1} & (Constant) & 13.818 & 1.985 & & 6.962 & .000 \\
\hline & $\mathrm{X} 1$ & .220 & .068 & .356 & 3.261 & .002 \\
\hline & $\mathrm{X} 2$ & .249 & .072 & .337 & 3.466 & .001 \\
\hline & X3 & .212 & .053 & .425 & 4.000 & .000 \\
\hline
\end{tabular}

Dari Tabel 9 diperoleh nilai $t_{\text {hitung }}$ masingmasing variabel. Nilai $t_{\text {hitung }}$ tersebut selanjutnya dibandingkan dengan nilai $t_{\text {tabel }}$ pada tingkat kepercayaan $95 \%$ atau $\alpha=0,05$. Nilai $t_{\text {tabel }}$ pada df 3:42 dengan $\alpha=0,05$ adalah 2.014.

a) Pengaruh parsial dari variabel manajemen perubahan $\left(\mathrm{X}_{1}\right)$ diperoleh dengan nilai $\mathrm{t}_{\text {hitung }}$ sebesar 3.261, dengan demikian $t_{\text {hitung }}>t_{\text {tabel }}$ (3.261 > 2.014) dengan nilai signifikan sebesar $0.002<0.05$, yang berarti bahwa variabel manajemen perubahan $\left(\mathrm{X}_{1}\right)$ berpengaruh positif dan signifikan terhadap kinerja pegawai Badan Penyelenggara Jaminan Sosial (BPJS) Kesehatan Cabang Padang Sidimpuan

b) Pengaruh parsial dari variabel budaya organisasi $\left(\mathrm{X}_{2}\right)$ diperoleh dengan nilai $\mathrm{t}_{\text {hitung }}$ sebesar 3.466, dengan demikian $t_{\text {hitung }}>t_{\text {tabel }}$ (3.466 > 2.014) dengan nilai signifikan sebesar $0.001<0.05$, yang berarti bahwa variabel budaya organisasi $\left(\mathrm{X}_{2}\right)$ berpengaruh positif dan signifikan terhadap kinerja pegawai Badan Penyelenggara Jaminan Sosial (BPJS) Kesehatan Cabang Padang Sidimpuan. 
c) Pengaruh parsial dari variabel kualitas kerja $\left(\mathrm{X}_{3}\right)$ diperoleh dengan nilai $\mathrm{t}_{\text {hitung }}$ sebesar 4.000 , dengan demikian $t_{\text {hitung }}>t_{\text {tabel }}(4.000>$ 2.014) dengan nilai signifikan sebesar 0.000 $<0.05$, yang berarti bahwa variabel kualitas kerja $\left(X_{3}\right)$ berpengaruh positif dan signifikan terhadap kinerja pegawai Badan Penyelenggara Jaminan Sosial (BPJS) Kesehatan Cabang Padang Sidimpuan.

\subsection{Uji Determinasi (R Square)}

Koefisien Determinasi

Model Summary ${ }^{\text {b }}$

\begin{tabular}{|l|l|l|l|l|l|l|l|}
\hline Model & $\mathrm{R}$ & $\mathrm{R}$ Square & $\begin{array}{l}\text { Adjusted } \\
\text { Square }\end{array}$ & & & & $\begin{array}{l}\text { Std. Error of } \\
\text { the Estimate }\end{array}$
\end{tabular}

a. Predictors: (Constant), X3, X2, X1

b. Dependent Variable: $Y$

Nilai koefisien determinasi sebesar 0,609 berarti bahwa terhadap kinerja pegawai Badan Penyelenggara Jaminan Sosial (BPJS) Kesehatan Cabang Padang Sidimpuan dapat dijelaskan oleh perubahan manajemen perubahan, budaya organisasi dan kualitas kerja sebesar $60.9 \%$, sedangkan sisanya sebesar $39.1 \%$ dipengaruhi oleh variable lain yang tidak dianalisis dalam penelitian ini.

\section{Kesimpulan}

Berdasarkan pada analisis dan evaluasi data di atas, maka kesimpulan dari penelitian ini adalah

1) Variabel manajemen perubahan $\left(X_{1}\right)$ berpengaruh positif dan signifikan terhadap kinerja pegawai Badan Penyelenggara Jaminan Sosial (BPJS) Kesehatan Cabang Padang Sidimpuan dengan nilai $t_{\text {hitung }}>t_{\text {tabel }}(3.261>2.014)$.

2) Variabel budaya organisasi $\left(X_{2}\right)$ berpengaruh positif dan signifikan terhadap kinerja pegawai Badan Penyelenggara Jaminan Sosial (BPJS) Kesehatan Cabang Padang Sidimpuan dengan nilai $t_{\text {hitung }}>t_{\text {tabel }}(3.466>2.014)$.

3) Variabel kualitas kerja $\left(X_{3}\right)$ berpengaruh positif dan signifikan terhadap kinerja pegawai Badan Penyelenggara Jaminan Sosial (BPJS) Kesehatan Cabang Padang Sidimpuan dengan nilai $t_{\text {hitung }}>t_{\text {tabel }}(4.000$ $>2.014)$.

4) Variabel manajemen perubahan, budaya organisasi dan kualitas kerja secara simultan berpengaruh signifikan terhadap kinerja pegawai Badan Penyelenggara Jaminan Sosial (BPJS) Kesehatan Cabang
Padang Sidimpuan dengan nilai Fhitung (23.799) > Ftabel $(2,81)$.

\section{DAFTAR PUSTAKA}

Ahcmad S. Rucky. 2010. Sistem Manajemen Kinerja, Bumi Aksara. Jakarta.

Amirullah, dan Hanafi, Rindyah. 2012.Pengantar Manajemen. Yogyakarta Graha Ilmu.

Arifana, D 2014 Pengaruh Manajemen Perubahan Terhadap Gaya Kepemimpinan Serta Dampaknya Pada Motivasi Kerja dan Kinerja Karyawan di PT. Bank Tabungan Pensiun Nasional Purna Bakti Cabang Jember. Jurnal, Dikses pada 01 Maret 2018.

Barker, Alan (2012), Mengelola Sumber Daya Manusia, PT. Gramedia, Jakarta.

Dessler, Garry (2010), Manajemen Sumber Daya Manusia, PT. Preshelindo, Jakarta.

Gibson, James L., Ivancevich, John M., Donnely, James H., and Konopaske (2010) Organizations: Behavior, Structure, Processes, New York, McGraw Hill.

Handoko T, Hani (2010), Manajemen Personalia dan Sumber Daya Manusia, Edisi Kedua, BPFE Yogyakarta.

Haryati (2013)"Pengaruh Manajemen Perubahan dan Kualitas kerjaTerhadap KinerjaPegawai pada dinas Kesehatan Kota Cimahi”.Skripsi, Universitas Islam Bandung.

Haryono (2015) "Pengaruh Kepemimpinan dan Disiplin Kerja dan Budaya organisasiTerhadap Kinerja Pegawai DPRD Kabupaten Madiun". Skripsi, Universitas Sebelas Maret.

Hasibuan, Malayu, SP (2010), Manajemen 
Sumber Daya Manusia, PT. Bumi Akasara Jakarta.

Hasibuan,

Melayu

SP.

(2010.)OrganisasidanMotivasi.Jakarta PT. BumiAksara.

Hidayati (2014) "Pengaruh Manajemen Perubahan, Budaya Organisasi dan Kualitas kerjaTerhadap Kinerja pegawai"'(Studi pada pegawai Perum Bulog Divisi Regional Jakarta)

Husnan (2015), Manajemen Personalia dan Sumber Daya Manusia, Edisi Kedua, BPFE Yogyakarta.

Mangkunegara, Anwar, Prabu. (2010). Evaluasi Kinerja SDM, Cetakan 4, Bandung : RefikaAditama

Martoyo, Susili (2010), Manajemen Sumber Daya Manusia, Edisi Ketiga, Cetakan Keempat, Ghalia Jakarta

Mathis, Robert L dan Jackson, Jhon H. 2012.Manajemen SDM. Jakarta :SalembaEmpat.

Prof. Dr. J. Winardi, 2013. Manajemen Perubahan (Management of Change), Penerbit Prenada.

Ridwan. (2010). SkalaPengukuranVariabelVariabelBandung :Alfabeta.

Robbins and Judge. 2010. Perilaku Organisasi, Edisi Duabelas. Jakarta : Salemba Empat.

Robbins, Stephen P. (2011). PerilakuOrganisasiJilid I. Yogyakarta :Aditya Media.

Santoso, Singgih (2010), SPSS Statistik Parametrik, PT. Alex Media Komputindo, Kelompok Gramedia Jakarta.

Sevilla, Consuelo G. et. al (2010). Research Methods. Rex Printing Company. Quezon City.

Siagian, Sondang. P, (2012), Manajemen Sumber Daya Manusia, Cetakan Kesembilan,Bumi Aksara, Jakarta.

Simbolon, R danAnisah, H.U. 2013.Pengaruh Perubahan Organisasi dan Budaya Organisasi Terhadap kinerja Pegawai Studi Pada Kantor Pelayanan Kekayaan Negara dan Lelang Banjarmasin. Jurnal Wawasan Manajemen, Vol 1 No 1 Februari 2013.

Sinungan (2011), Filsafat Administrasi, Gunung Agung Jakarta.

Stoner (2009), Manajemen Tenaga , Sinar Baru Bandung.

Sugito.2011. Pengaruh Manajemen Perubahan terhadap Kemajuan Perusahaan Pada PD RHP Kota Medan. Jurnal, Diaksespada 01 Maret 2018.
Suharti (2012) "Pengaruh Manajemen PerubahanTerhadap Kinerja Pegawai Pada Distanak Kabupaten Buleleng", Skripsi, Universitas Negeri Yogyakarta.

Tika, P. (2010). Budaya Organisasi Dan Peningkatan Kinerja Instansi. Jakarta: Bumi Aksara.

Wibowo. 2011. Managing Change PengantarManajemenPerubahan. Alfabeta. Bandung.

Widarno (2016) "Pengaruh kepemimpinan, Budaya organisasiTerhadap KinerjaPegawai BKD DIY'.Skripsi, Universitas Negeri Yogyakarta. 